\title{
Impact of diabetes mellitus on mortality in patients with acute heart failure: a prospective cohort study
}

Min Gyu Kong ${ }^{1 \dagger}$, Se Yong Jang ${ }^{2 \dagger}$, Jieun Jang ${ }^{3,4,5}$, Hyun-Jai Cho ${ }^{6}$, Sangjun Lee ${ }^{3,4,5}$, Sang Eun Lee ${ }^{7}$, Kye Hun Kim , Byung-Su Yoo ${ }^{9}$, Seok-Min Kang ${ }^{10}$, Sang Hong Baek ${ }^{11}$, Dong-Ju Choi ${ }^{12}$, Eun-Seok Jeon ${ }^{13}$, Jae-Joong Kim ${ }^{7}$, Myeong-Chan Cho ${ }^{14}$, Shung Chull Chae ${ }^{2}$, Byung-Hee Oh' ${ }^{6}$, Soo Lim² ${ }^{12}$, Sue K. Park ${ }^{3,4,5}$ and Hae-Young Lee $6,15^{*}$ (I)

\begin{abstract}
Background: Although more than one-third of the patients with acute heart failure (AHF) have diabetes mellitus (DM), it is unclear if DM has an adverse impact on clinical outcomes. This study compared the outcomes in patients hospitalized for AHF stratified by DM and left ventricular ejection fraction (LVEF).
\end{abstract}

Methods: The Korean Acute Heart Failure registry prospectively enrolled and followed 5625 patients from March 2011 to February 2019. The primary endpoints were in-hospital and overall all-cause mortality. We evaluated the impact of DM on these endpoints according to HF subtypes and glycemic control.

Results: During a median follow-up of 3.5 years, there were 235 (4.4\%) in-hospital mortalities and 2500 (46.3\%) overall mortalities. DM was significantly associated with increased overall mortality after adjusting for potential confounders (adjusted hazard ratio [HR] 1.11, 95\% confidence interval [CI] 1.03-1.22). In the subgroup analysis, DM was associated with higher a risk of overall mortality in heart failure with reduced ejection fraction (HFrEF) only (adjusted HR 1.14, 95\% Cl 1.02-1.27). Inadequate glycemic control (HbA1c $\geq 7.0 \%$ within 1 year after discharge) was significantly associated with a higher risk of overall mortality compared with adequate glycemic control ( $\mathrm{HbA1c}<7.0 \%)(44.0 \% \mathrm{vs}$. $36.8 \%$, log-rank $p=0.016$ ).

Conclusions: DM is associated with a higher risk of overall mortality in AHF, especially HFrEF. Well-controlled diabetes $(\mathrm{HbA} 1 \mathrm{c}<7.0 \%)$ is associated with a lower risk of overall mortality compared to uncontrolled diabetes.

Trial registration ClinicalTrial.gov, NCT01389843. Registered July 6, 2011. https://clinicaltrials.gov/ct2/show/NCT01 389843

Keywords: Diabetes mellitus, Acute heart failure, Left ventricular ejection fraction, Glycemic control

*Correspondence: hylee612@snu.ac.kr

${ }^{\dagger}$ Min Gyu Kong and Se Yong Jang equally contributed to this work

${ }^{15}$ Division of Cardiology, Department of Internal Medicine, Seoul National

University College of Medicine, 101 Daehak-ro, Jongno-gu, Seoul 03080, South Korea

Full list of author information is available at the end of the article

\section{Background}

Around 26 million people suffer from heart failure (HF) globally, and the prevalence is increasing with an increasing longevity, prevalence of risk factors, and improved survival in patients with cardiovascular diseases [1, 2]. In the United States, HF is the primary cause of hospitalization among patients aged $>65$ years [3]. Hospitalization for HF is associated with a high mortality and rate of re-hospitalization $[4,5]$. Around

c) The Author(s) 2020. This article is licensed under a Creative Commons Attribution 4.0 International License, which permits use, sharing, adaptation, distribution and reproduction in any medium or format, as long as you give appropriate credit to the original author(s) and the source, provide a link to the Creative Commons licence, and indicate if changes were made. The images or other third party material in this article are included in the article's Creative Commons licence, unless indicated otherwise in a credit line to the material. If material is not included in the article's Creative Commons licence and your intended use is not permitted by statutory regulation or exceeds the permitted use, you will need to obtain permission directly from the copyright holder. To view a copy of this licence, visit http://creativecommons.org/licenses/by/4.0/. The Creative Commons Public Domain Dedication waiver (http://creativecommons.org/publicdomain/zero/1.0/) applies to the data made available in this article, unless otherwise stated in a credit line to the data. 
$75 \%$ patients with HF have $\geq 1$ comorbidity, and these comorbidities make overall clinical outcomes worse [6]. In a recent meta-analysis, patients with diabetes mellitus (DM) were suggested to have a two-fold increase in the risk of HF [7]. DM is present in $35 \%$ patients hospitalized with acute HF [8]. Multiple factors such as ischemia, hypertension, and extracellular fluid volume expansion are involved in the pathogenesis of HF in DM $[9,10]$. While DM is associated with an increased cardiovascular morbidity and mortality in patients with chronic HF with reduced left ventricular ejection fraction (HFrEF) [11, 12], its independent impact on in-hospital and long-term outcomes after HF hospitalization is unclear. Data from some large registries and clinical trials suggest that DM is associated with worse in-hospital and post-discharge outcomes in patients with acute HF [13-18]. Other studies do not suggest a significant association of DM with mortality in patients hospitalized for HF after adjusting for confounding factors [19-22]. Thus, the independent association of DM with mortality in patients with HF remains unknown. It is also unclear if DM has similar adverse impact across HF subtypes such as HFrEF, HF with preserved ejection fraction (HFpEF), or HF with mid-range ejection fraction (HFmrEF).

We compared acute HF-associated in-hospital and overall all-cause mortality in patients with and without DM using the Korean Acute Heart Failure Registry (KorAHF) [23]. We also compared the outcomes in each HF subtype.

\section{Methods}

\section{Study population}

We evaluated the patients with acute HF enrolled in the KorAHF registry (ClinicalTrial.gov identifier, NCT01389843) [23]. Briefly, the KorAHF registry is a prospective multicenter cohort study of 5625 patients admitted for acute heart failure (AHF) in 10 tertiary university hospitals between March 2011 and February 2014 who have been followed for $>5$ years until February 2019 . Patients who had signs or symptoms of HF and met $\geq 1$ of the following criteria were enrolled in this registry: (1) lung congestion or (2) objective evidence of left ventricular (LV) systolic dysfunction or (3) structural heart disease.

We excluded 210 patients where there was no information on LV ejection fraction (LVEF) and 21 patients who were lost to follow-up. Finally, 5394 patients with AHF and known DM status and LVEF were enrolled for analyses (Fig. 1).

\section{Data collection and outcome definition}

Data were collected at each hospital and entered into a web-based Clinical Research and Trial (iCReaT) system case-report form of the Korea National Institute of Health. Detailed information was collected at the time of admission, and follow-up data were collected from the patients by the attending physician at 30 days and 3, 6, 12, $24,36,48$, and 60 months after discharge. Data on patient demographics, medical history, physical signs, laboratory test results, electrocardiography, echocardiography, medications, and outcomes were collected. The mortality

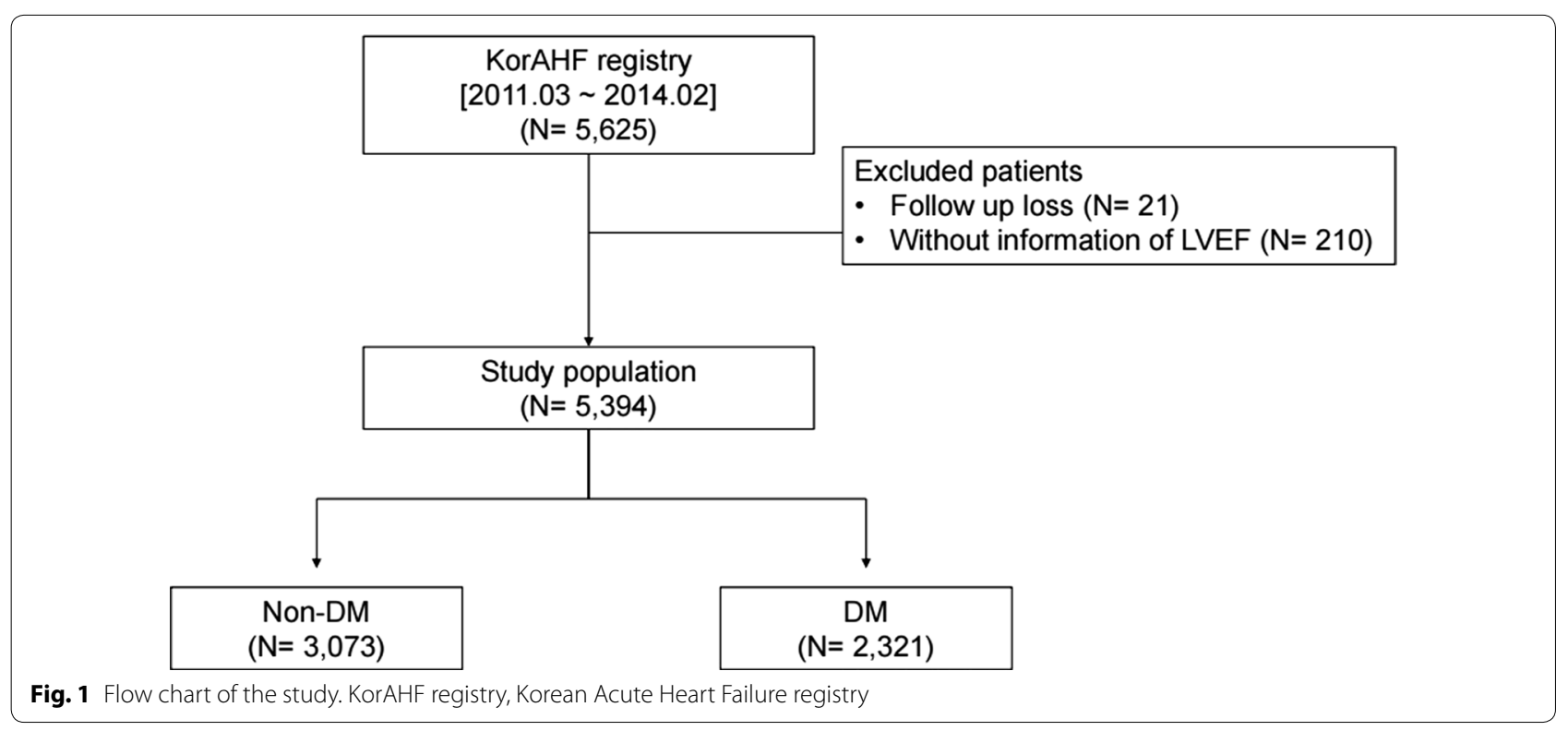


data for patients lost to follow-up was collected from the National Insurance data or National Death Records.

\section{Definition of DM and glycemic control}

DM was defined as self-reported, history of anti-hyperglycemic agent use, or newly diagnosed during hospitalization [17]. Newly diagnosed DM was defined as a glycated hemoglobin $(\mathrm{HbA} 1 \mathrm{c}) \geq 6.5 \%$ when measured after a random glucose level $\geq 200 \mathrm{mg} / \mathrm{dl}$ at enrollment. We additionally classified DM patients based on HbA1c levels measured at the follow-up visit $\leq 1$ year from discharge. We defined well-controlled and uncontrolled $\mathrm{DM}$ by an $\mathrm{HbA1c}<7.0 \%$ and $\geq 7.0 \%$ at the follow-up visit, respectively. According to LVEF, we categorized patients with AHF into 3 groups: $\mathrm{LVEF}<40 \%$ (HFrEF), $40 \% \leq \mathrm{LVEF}<50 \%$ (HFmrEF), and LVEF $\geq 50 \%$ (HFpEF).

\section{Statistical analysis}

Baseline characteristics as per DM status were compared using the $\chi^{2}$ test for categorical variables and the unpaired Student's $t$-test for continuous variables. Kaplan-Meier survival curves as per DM status were compared using the log-rank test. We used the multivariable Cox proportional hazard regression model to evaluate the association between DM and mortality in patients with AHF. Potential confounders which were different at baseline in patients with and without DM, or were considered clinically significant including age, sex, body mass index (BMI), etiology of HF (ischemic or non-ischemic), prior admission for HF, use of parenteral inotropic agents, serum creatinine concentration $(<2.0$ or $\geq 2.0 \mathrm{mg} / \mathrm{dL})$, elevated brain natriuretic peptides (BNP) $(\geq 500 \mathrm{pg} /$ $\mathrm{mL}$ ) or N-terminal pro-brain natriuretic peptides (NTproBNP) $(\geq 1000 \mathrm{pg} / \mathrm{mL})$, New York Heart Association (NYHA) class (III-IV or I-II) on admission, and smoking status (current or ex-smoker vs. never-smoker) were adjusted for in the multivariable model. An interaction between DM and potential confounders was assessed by adding interaction terms in the Cox proportional hazard regression model. All p-values were two-sided, and p-values $<0.05$ were considered statistically significant. Statistical analyses were performed using SAS software version 9.4 (SAS Institute Inc., Cary, NC, USA) and R version 3.6.0 with packages ("survival", and "survminer").

\section{Results}

\section{Baseline characteristics}

In the study population, 2321 patients with AHF had DM (43.0\%) (Table 1). Patients with DM had a higher prevalence of risk factors like old age, obesity, hypertension, ischemic heart disease, chronic kidney disease, and cerebrovascular disease. Patients with DM had a higher proportion of patients with a $B N P \geq 500 \mathrm{pg} / \mathrm{mL}$ or
NT-proBNP $\geq 1000 \mathrm{pg} / \mathrm{mL}$, NYHA class III-IV on admission, acute pulmonary edema on chest X-ray, a higher level of systolic blood pressure, C-reactive protein, serum potassium and creatinine concentration, and lower serum sodium concentration and LVEF compared to those without DM. Besides, patients with DM were more likely to be on parenteral diuretics, inotropic agents, and vasodilators. However, aldosterone antagonists were prescribed less frequently in patients with DM.

All patients underwent echocardiography during their index admission (Table 1). There were no significant differences in the LV end-diastolic dimension (LVEDD) and LV end-systolic dimension (LVESD) between the two groups. However, there was a significant difference in the LVEF $(38.5 \pm 15.9 \%$ vs. $36.7 \pm 15.0 \%, \mathrm{p}<0.001)$. Furthermore, LV diastolic function parameters such as E/e' $(20.1 \pm 10.8$ vs. $22.7 \pm 12.2, \mathrm{p}<0.001)$ and right ventricular (RV) systolic pressure $(43.2 \pm 14.9 \mathrm{mmHg}$ vs. $44.9 \pm 15.4 \mathrm{mmHg}, \mathrm{p}<0.001)$ were worse in patients with DM. Conversely, patients without DM had a larger LA volume index $\left(66.7 \pm 41.9 \mathrm{~mL} / \mathrm{m}^{2}\right.$ vs. $59.6 \pm 42.0 \mathrm{~mL} / \mathrm{m}^{2}$, $\mathrm{p}<0.001)$.

\section{In-hospital and overall mortality as per DM status}

During a median follow-up of 3.5 years, there were 235 (4.4\%) deaths during the index hospitalization, and 2500 (46.3\%) deaths during the overall follow-up period. Patients with DM had a higher incidence of in-hospital mortality and overall mortality compared to patients without DM (Fig. 2). After adjusting for potential confounders including age, sex, BMI, etiology of heart failure (ischemic vs. non-ischemic), prior admission for HF, parenteral inotropic use, serum creatinine concentration, elevated BNP/NT-proBNP, NYHA class III-IV on admission, and smoking status, DM was still independently associated with overall mortality (adjusted hazard rate [HR] 1.11, 95\% confidence interval [CI] 1.03-1.22).

\section{Independent predictors of in-hospital and overall mortality} Results of multivariable Cox proportional hazard regression for in-hospital and overall all-cause mortality are reported in Table 2. DM was not independently associated with an increased in-hospital mortality (HR 0.81, $95 \% \mathrm{CI} 0.61-1.07, \mathrm{p}=0.137$ ). Use of parenteral inotropes, age, ischemic etiology, and a higher serum creatinine concentration also independently predicted in-hospital mortality.

DM was an independent predictor for overall mortality (HR 1.11, 95\% CI 1.03-1.22, $\mathrm{p}=0.013$ ). Other variables, such as old age, male sex, higher BMI, ischemic etiology, acute decompensated HF, use of parenteral inotropes, high concentrations of serum creatinine and BNP/NTproBNP during index hospitalization, and NYHA class 
Table 1 Baseline clinical characteristics according to diabetes mellitus (DM)

\begin{tabular}{|c|c|c|c|c|}
\hline Variables & All patients $(\mathrm{N}=5394)$ & Non-DM (N=3073) & $\mathrm{DM}(\mathrm{N}=2321)$ & $P$-value \\
\hline Age & $68.5 \pm 14.5$ & $67.6 \pm 15.9$ & $69.6 \pm 12.3$ & $<0.001$ \\
\hline Body mass index $\left(\mathrm{kg} / \mathrm{m}^{2}\right)$ & $23.0 \pm 3.9$ & $23.0 \pm 3.9$ & $23.7 \pm 3.8$ & $<0.001$ \\
\hline Male, N (\%) & $2872(53.2)$ & $1596(51.9)$ & $1277(55.0)$ & 0.023 \\
\hline Current smoker, N (\%) & $961(17.8)$ & $546(17.8)$ & $415(17.9)$ & 0.086 \\
\hline \multicolumn{5}{|l|}{ Risk factors, N (\%) } \\
\hline Hypertension & $3183(59.0)$ & $1554(50.6)$ & $1629(70.2)$ & $<0.001$ \\
\hline Ischemic heart disease & $1501(27.8)$ & $636(20.7)$ & $865(37.2)$ & $<0.001$ \\
\hline Atrial fibrillation & $1523(28.2)$ & $921(30.0)$ & $602(25.9)$ & 0.001 \\
\hline Chronic lung disease & $608(11.3)$ & $350(11.4)$ & $258(11.1)$ & 0.492 \\
\hline Chronic kidney disease & $756(14.0)$ & $277(9.0)$ & $479(20.6)$ & $<0.001$ \\
\hline Cerebrovascular disease & $807(15.0)$ & $405(13.2)$ & $402(17.3)$ & $<0.001$ \\
\hline Previous heart failure & $2539(47.1)$ & $1380(44.9)$ & $1159(49.9)$ & $<0.001$ \\
\hline \multicolumn{5}{|l|}{ Physical and laboratory findings } \\
\hline $\mathrm{SBP}, \mathrm{mmHg}$ & $131.4 \pm 30.1$ & $130.4 \pm 29.4$ & $132.8 \pm 30.9$ & 0.003 \\
\hline $\mathrm{DBP}, \mathrm{mmHg}$ & $78.7 \pm 18.7$ & $79.2 \pm 18.8$ & $78.1 \pm 18.6$ & 0.028 \\
\hline Heart rate, beats/min & $92.8 \pm 25.9$ & $92.5 \pm 26.4$ & $93.1 \pm 25.2$ & 0.379 \\
\hline Glucose, mg/dL & $155.3 \pm 76.7$ & $129.6 \pm 47.8$ & $189.1 \pm 94.1$ & $<0.001$ \\
\hline Total cholesterol, mg/dL & $151.8 \pm 43.2$ & $153.9 \pm 42.2$ & $149.2 \pm 44.4$ & $<0.001$ \\
\hline $\mathrm{BNP} \geq 500 \mathrm{pg} / \mathrm{mL}$ or NT-proBNP $\geq 1000 \mathrm{pg} / \mathrm{mL}$ & $4047(75.0)$ & $2267(73.8)$ & $1780(76.7)$ & 0.014 \\
\hline $\mathrm{CRP}, \mathrm{mg} / \mathrm{dL}$ & $2.4 \pm 4.3$ & $2.1 \pm 3.5$ & $2.9 \pm 5.0$ & $<0.001$ \\
\hline $\mathrm{hsCRP}, \mathrm{mg} / \mathrm{dL}$ & $2.3 \pm 4.2$ & $2.0 \pm 3.8$ & $2.6 \pm 4.6$ & $<0.001$ \\
\hline Sodium, $\mathrm{mmol} / \mathrm{L}$ & $137.5 \pm 4.8$ & $138.0 \pm 4.6$ & $136.8 \pm 5.0$ & $<0.001$ \\
\hline Potassium, mmol/L & $4.4 \pm 0.7$ & $4.3 \pm 0.6$ & $4.5 \pm 0.8$ & $<0.001$ \\
\hline BUN, mg/dL & $26.1 \pm 16.3$ & $23.7 \pm 14.3$ & $29.2 \pm 18.3$ & $<0.001$ \\
\hline Creatinine, $\mathrm{mg} / \mathrm{dL}$ & $1.5 \pm 1.5$ & $1.3 \pm 1.3$ & $1.7 \pm 1.6$ & $<0.001$ \\
\hline NYHA class III-IV, N (\%) & $4582(84.9)$ & $2558(83.2)$ & $2024(87.2)$ & $<0.001$ \\
\hline Acute pulmonary edema on chest X-ray, N (\%) & $1039(19.3)$ & $502(16.3)$ & $537(23.1)$ & $<0.001$ \\
\hline \multicolumn{5}{|l|}{ Echocardiographic findings } \\
\hline LVEDD, mm & $57.4 \pm 10.1$ & $57.5 \pm 10.6$ & $57.4 \pm 9.3$ & 0.863 \\
\hline LVESD, mm & $45.2 \pm 12.3$ & $45.1 \pm 12.8$ & $45.4 \pm 11.7$ & 0.302 \\
\hline LVEF (\%) & $37.8 \pm 15.6$ & $38.5 \pm 15.9$ & $36.7 \pm 15.0$ & $<0.001$ \\
\hline $\mathrm{LA}$ volume index, $\mathrm{mL} / \mathrm{m}^{2}$ & $63.8 \pm 42.1$ & $66.7 \pm 41.9$ & $59.6 \pm 42.0$ & $<0.001$ \\
\hline $\mathrm{E}^{\prime}, \mathrm{cm} / \mathrm{s}$ & $5.0 \pm 2.3$ & $5.2 \pm 2.1$ & $4.8 \pm 2.5$ & $<0.001$ \\
\hline $\mathrm{S}^{\prime}, \mathrm{cm} / \mathrm{s}$ & $5.1 \pm 2.0$ & $5.1 \pm 2.1$ & $5.0 \pm 1.9$ & 0.026 \\
\hline$E / E^{\prime}$ & $21.2 \pm 11.5$ & $20.1 \pm 10.8$ & $22.7 \pm 12.2$ & $<0.001$ \\
\hline RVSP & $43.9 \pm 15.1$ & $43.2 \pm 14.9$ & $44.9 \pm 15.4$ & $<0.001$ \\
\hline \multicolumn{5}{|l|}{ Management, N (\%) } \\
\hline Parenteral diuretics & $4062(75.3)$ & $2222(72.3)$ & $1840(79.3)$ & $<0.001$ \\
\hline Parenteral inotropics & $1672(31.0)$ & $760(24.7)$ & $912(39.3)$ & $<0.001$ \\
\hline Parenteral vasodilators & $2231(41.4)$ & $1105(36.0)$ & $1126(48.5)$ & $<0.001$ \\
\hline ACEIs/ARBs at admission & $3383(62.7)$ & $1977(64.3)$ & $1406(60.6)$ & 0.001 \\
\hline ACEIs/ARBs at discharge & $3601(66.8)$ & $2117(68.9)$ & $1484(63.9)$ & $<0.001$ \\
\hline Beta-blockers at admission & $2054(38.1)$ & $1183(38.5)$ & $871(37.5)$ & 0.001 \\
\hline Beta-blockers at discharge & $2725(50.5)$ & $1533(49.9)$ & $1192(51.4)$ & 0.285 \\
\hline AAs at admission & $2206(40.9)$ & $1379(44.9)$ & $827(35.6)$ & $<0.001$ \\
\hline AAs at discharge & $2443(45.3)$ & $1472(47.9)$ & $971(41.8)$ & $<0.001$ \\
\hline Warfarin at discharge & $1531(28.4)$ & $965(31.4)$ & $566(24.4)$ & $<0.001$ \\
\hline Heart transplantation & $69(1.3)$ & $13(0.4)$ & $56(2.4)$ & $<0.001$ \\
\hline
\end{tabular}

Values are presented as mean \pm standard deviation, or $\mathrm{n}(\%)$

$D M$ diabetes mellitus, SBP systolic blood pressure, DBP diastolic blood pressure, BNP brain natriuretic peptides, NT-proBNP N-terminal pro-brain natriuretic peptides, hsCRP high sensitivity C-reactive protein, CRP C-reactive protein, $B U N$ blood urea nitrogen, $L V E D D$ left ventricular end-diastolic dimension, $L V E D V$ left ventricular enddiastolic volume, $L V E F$ left ventricular ejection fraction, $L A$ left atrium, RVSP right ventricular systolic pressure, $A C E / s$ angiotensin converting enzyme inhibitors, $A R B s$ angiotensin receptor blockers, $A A$ s aldosterone antagonists 


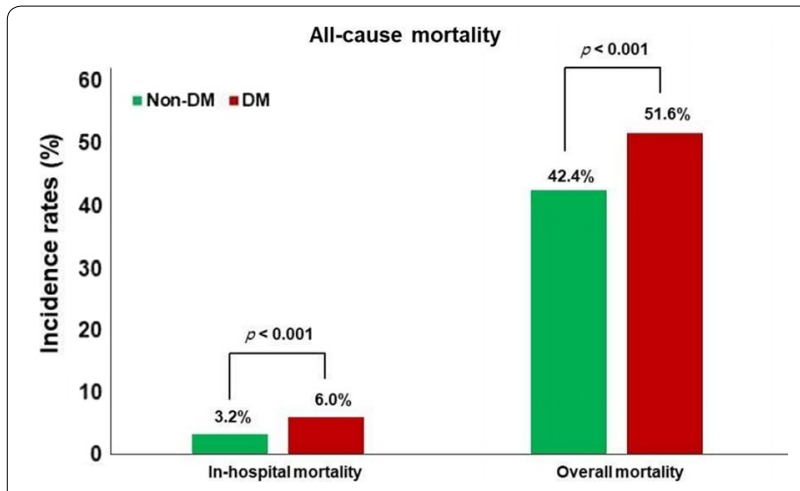

Fig. 2 Comparison of in-hospital and overall all-cause mortality as per DM status

Table 2 Independent predictors of in-hospital and overall mortality on multivariable Cox proportional hazard regression model

\begin{tabular}{|c|c|c|}
\hline Variables & Adjusted $\mathrm{HR}^{\mathrm{a}}$ & $P$ value \\
\hline \multicolumn{3}{|l|}{ In-hospital mortality } \\
\hline DM & $0.81(0.61-1.07)$ & 0.137 \\
\hline Age (years) & $1.03(1.02-1.04)$ & $<0.001$ \\
\hline Ischemic cause (vs non-ischemic cause) & $1.41(1.07-1.86)$ & 0.016 \\
\hline Parenteral inotropics usage & $5.14(3.43-7.68)$ & $<0.001$ \\
\hline Serum creatinine $\geq 2.0$ (vs $<2.0 \mathrm{mg} / \mathrm{dL})$ & $1.54(1.15-2.07)$ & 0.015 \\
\hline \multicolumn{3}{|l|}{ Overall mortality } \\
\hline $\mathrm{DM}$ & $1.11(1.03-1.22)$ & 0.013 \\
\hline Age (years) & $1.04(1.04-1.05)$ & $<0.001$ \\
\hline Sex (male) & $1.26(1.14-1.38)$ & $<0.001$ \\
\hline \multicolumn{3}{|l|}{ Body mass index $\left(\mathrm{kg} / \mathrm{m}^{2}\right)$} \\
\hline Underweight vs. Normal & $1.66(1.47-1.88)$ & $<0.001$ \\
\hline Overweight or obese vs. Normal & $0.80(0.73-0.89)$ & $<0.001$ \\
\hline Ischemic cause (vs non-ischemic cause) & $1.17(1.07-1.27)$ & $<0.001$ \\
\hline Prior admission history due to HF & $1.51(1.39-1.64)$ & $<0.001$ \\
\hline Parenteral inotropics usage & $1.41(1.30-1.55)$ & $<0.001$ \\
\hline Serum creatinine $\geq 2.0$ (vs $<2.0 \mathrm{mg} / \mathrm{dL})$ & $1.63(1.50-1.83)$ & $<0.001$ \\
\hline $\begin{array}{l}\text { Higher BNP ( } \geq 500) \text {, or NT-proBNP ( } \geq 1000) \\
\text { during index hospitalization }\end{array}$ & $1.32(1.22-1.49)$ & $<0.001$ \\
\hline NYHA class III-IV on admission & $1.35(1.22-1.49)$ & $<0.001$ \\
\hline
\end{tabular}

a Adjusted for age, sex, body mass index, etiology of heart failure (ischemic vs. non-ischemic), prior admission history due to HF, parenteral inotropics usage, creatinine concentration ( $<2.0$ vs. $\geq 2.0 \mathrm{mg} / \mathrm{dL}$ ), elevated BNP $(\geq 500)$ or NT-proBNP $(\geq 1000)$, NYHA class (III-IV or I-II) on admission, and smoking status (current or ex-smoker vs. never-smoker)

III-IV on admission also independently predicted higher overall mortality.

\section{In-hospital and overall mortality according to DM in subgroup by LVEF}

Patients with DM had a higher in-hospital mortality rate vs. patients without DM in all LVEF subgroups (HFrEF
Table 3 In-hospital and overall mortality according to DM in 3 subtypes of $\mathrm{HF}$

\begin{tabular}{|c|c|c|}
\hline $\begin{array}{l}\text { Diabetes mellitus } \\
\text { (DM) }\end{array}$ & $\begin{array}{l}\text { Unadjusted HR (95\% } \\
\mathrm{Cl})\end{array}$ & Adjusted HR $(95 \% \mathrm{CI})^{1}$ \\
\hline \multicolumn{3}{|l|}{ In-hospital mortality } \\
\hline \multicolumn{3}{|l|}{ LVEF $<40 \%$} \\
\hline Non-DM & 1.00 & 1.00 \\
\hline DM & $1.28(0.92-1.77)$ & $0.96(0.68-1.35)$ \\
\hline \multicolumn{3}{|l|}{$40 \% \leq \mathrm{LVEF}<50 \%$} \\
\hline Non-DM & 1.00 & 1.00 \\
\hline DM & $0.83(0.41-1.68)$ & $0.71(0.33-1.53)$ \\
\hline \multicolumn{3}{|l|}{$\mathrm{LVEF} \geq 50 \%$} \\
\hline Non-DM & 1.00 & 1.00 \\
\hline $\mathrm{DM}$ & $0.94(0.50-1.77)$ & $0.79(0.41-1.51)$ \\
\hline \multicolumn{3}{|l|}{ Overall mortality } \\
\hline \multicolumn{3}{|l|}{ LVEF $<40 \%$} \\
\hline Non-DM & 1.00 & 1.00 \\
\hline $\mathrm{DM}$ & $1.48(1.33-1.64)$ & $1.14(1.02-1.27)$ \\
\hline \multicolumn{3}{|l|}{$40 \% \leq \mathrm{LVEF}<50 \%$} \\
\hline Non-DM & 1.00 & 1.00 \\
\hline $\mathrm{DM}$ & $1.19(0.98-1.44)$ & $0.99(0.80-1.22)$ \\
\hline \multicolumn{3}{|l|}{ LVEF $\geq 50 \%$} \\
\hline Non-DM & 1.00 & 1.00 \\
\hline DM & $1.15(0.98-1.35)$ & $1.13(0.96-1.34)$ \\
\hline
\end{tabular}

Adjusted for age, sex, body mass index, etiology of heart failure (ischemic vs. non-ischemic), prior admission history due to $\mathrm{HF}$, parenteral inotropics usage, creatinine concentration ( $<2.0 \mathrm{vs} . \geq 2.0 \mathrm{mg} / \mathrm{dL}$ ), elevated BNP $(\geq 500)$ or NTproBNP ( $\geq 1000$ ), NYHA class (III-IV or I-II) on admission, and smoking status (current or ex-smoker vs. never-smoker)

$7.1 \%$ vs. $3.4 \%$, HFmrEF $4.3 \%$ vs. $3.2 \%$, HFpEF $3.8 \%$ vs. $2.7 \%)$. However, there was no significant association of DM with higher in-hospital mortality rate after adjusting for potential confounders (HFrEF, adjusted HR 0.96, 95\% CI 0.68-1.35, HFmrEF, adjusted HR 0.71, 95\% CI 0.33-1.53, HFpEF, adjusted HR 0.79, 95\% CI 0.41-1.51) (Table 3).

DM had differential impact on overall mortality as per the HF subtype. In HFrEF, DM was significantly associated with an increased risk of overall mortality after adjusting for potential confounders (adjusted HR 1.14, 95\% CI 1.02-1.27). However, DM was not significantly associated with overall mortality in patients with HFmrEF (adjusted HR 0.99, 95\% CI 0.80-1.22) and HFpEF (adjusted HR 1.13, 95\% CI 0.96-1.34) (Table 3). The Kaplan-Meier analysis also revealed significantly worse overall mortality in patients with HFrEF and DM vs. HFrEF and no DM $(40.2 \%$ vs. $52.7 \%$, log-rank p $<0.001)$ (Fig. 3). 


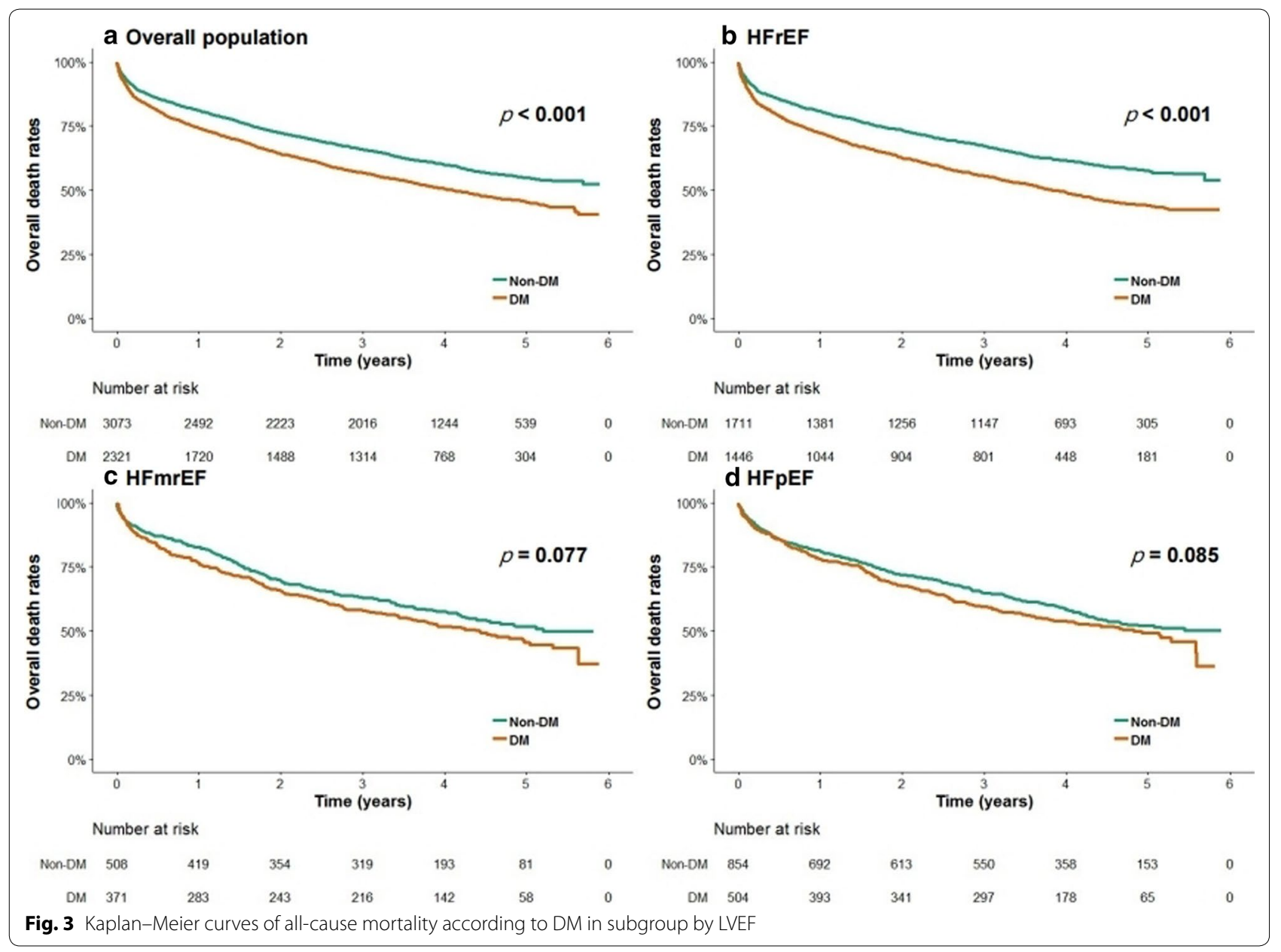

\section{Overall mortality as per the prespecified subgroup and glycemic control}

Figure 4 shows the association between DM and overall mortality in a stratified group as per the potential confounders, including age, sex, ischemic etiology, hypertension, chronic kidney disease, de novo $\mathrm{HF}, \mathrm{LVEF}<40 \%$, and smoking status. The impact of DM on overall mortality was generally consistent across stratified subgroups (p-interaction $\geq 0.05$ ). However, there was a significant difference in the impact of $\mathrm{DM}$ on overall mortality between smoker (current or ex-smoker) and never-smoker ( $\mathrm{p}$ for interaction $=0.022$ ).

Figure 5 shows that patients with uncontrolled DM $(\mathrm{HbA} 1 \mathrm{c} \geq 7.0 \%)$ had significantly higher overall mortality compared to patients with well-controlled DM $(\mathrm{HbA} 1 \mathrm{c}<7.0 \%)$ by Kaplan-Meier analysis $(44.0 \%$ vs. $36.8 \%, \log$-rank $\mathrm{p}=0.016)$.

\section{Discussion}

The main findings of our study are as follows: (1) patients with AHF and DM have a significantly higher in-hospital and overall mortality vs. patients with AHF and no DM; (2) DM was significantly associated with a higher overall mortality even after adjusting for potential confounding factors including age, sex, BMI, HF etiology, renal function, and HF severity; (3) DM had a significant association with higher overall mortality in HFrEF, but not HFmrEF and HFpEF; (4) patients with poor glycemic control after discharge (HbA1c $\geq 7.0 \%$ ) had a higher overall mortality vs. patients with adequate glycemic control (HbA1c $<7.0 \%)$.

Previous studies in HF have compared the clinical characteristics and outcomes in patients with and without DM. However, there are few reports comparing clinical outcomes stratified by DM in HFpEF [12, 24, 25]. Moreover, there is no data from a large registry or clinical trials 


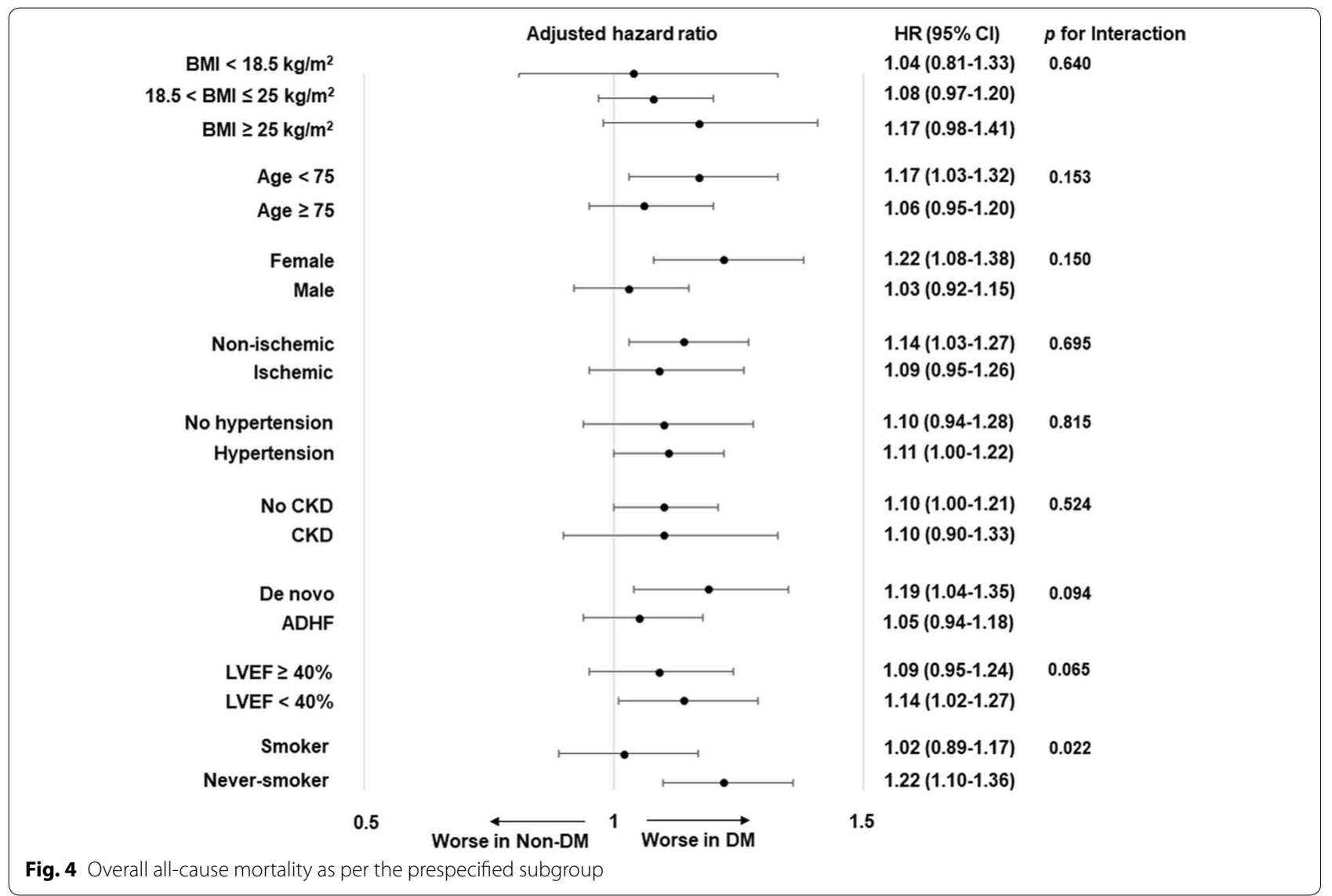

in patients with HFmrEF. The CHARM program demonstrated that DM was significantly associated with a higher mortality and morbidity in HFrEF and HFpEF [11]. Another large-scale study from the I-PRESERVE trial (Irbesartan in Heart Failure with Preserved Ejection Fraction) showed that patients with DM had more significant structural and functional echocardiographic abnormalities and worse clinical outcomes compared to patients without DM in HFpEF [24]. A recent prospective HFpEF study showed a significant association of DM with longterm mortality in women, but not in men [25]. Similar to HFrEF, these studies demonstrate a significant associations of DM with higher mortality in HFpEF. The mechanisms for poor prognosis of HF with DM are unclear.

Some of these mechanisms are: (1) DM causes microangiopathy, myocardial fibrosis, and autonomic neuropathy and these lead to diabetic cardiomyopathy [26]; (2) hyperglycemia leads to lipid accumulation in the heart, and this can cause cellular damage by lipotoxicity [27]; (3) lipid accumulation, collagen deposition and fibrosis, and hyperinsulinemia due to insulin resistance increases risk of hypertrophy of the heart [28, 29]; (4) DM may promote extracellular matrix expansion which is associated with a higher mortality in HF [30]; (5) impaired branched-chain amino acids catabolism and insulin signaling are associated with HF [31]; (6) distinct pathways related to inflammation, protein phosphorylation, and neutrophil degranulation are associated with DM in HF [32].

Why DM was not associated with an increased mortality in HFpEF and HFmrEF is unclear. The LVEF cutoff to classify HF in previous studies was different from the current updated guidelines for the diagnosis and treatment of HF that are accepted and used in clinical practice [33]. The CHARM program did not provide detailed echocardiographic data. The I-PRESERVE trial used an LVEF cutoff of 45\%, and echocardiographic data were shown for $<20 \%$ of the whole study population. Our results require cautious interpretation. In general, patients with DM had a higher overall mortality, but this association was not statistically significant in HFpEF and HFmrEF after adjusting for risk factors such as old age, ischemic etiology, and severity of initial presentation.

Patients with HFmrEF have similar clinical characteristics as patients with HFpEF [34-37]. Recent studies demonstrate that mortality rates in HFmrEF are similar to those in HFpEF [35-38]. Although there are no studies on the association of DM with mortality in patients with HFmrEF, our study shows that this association is different 


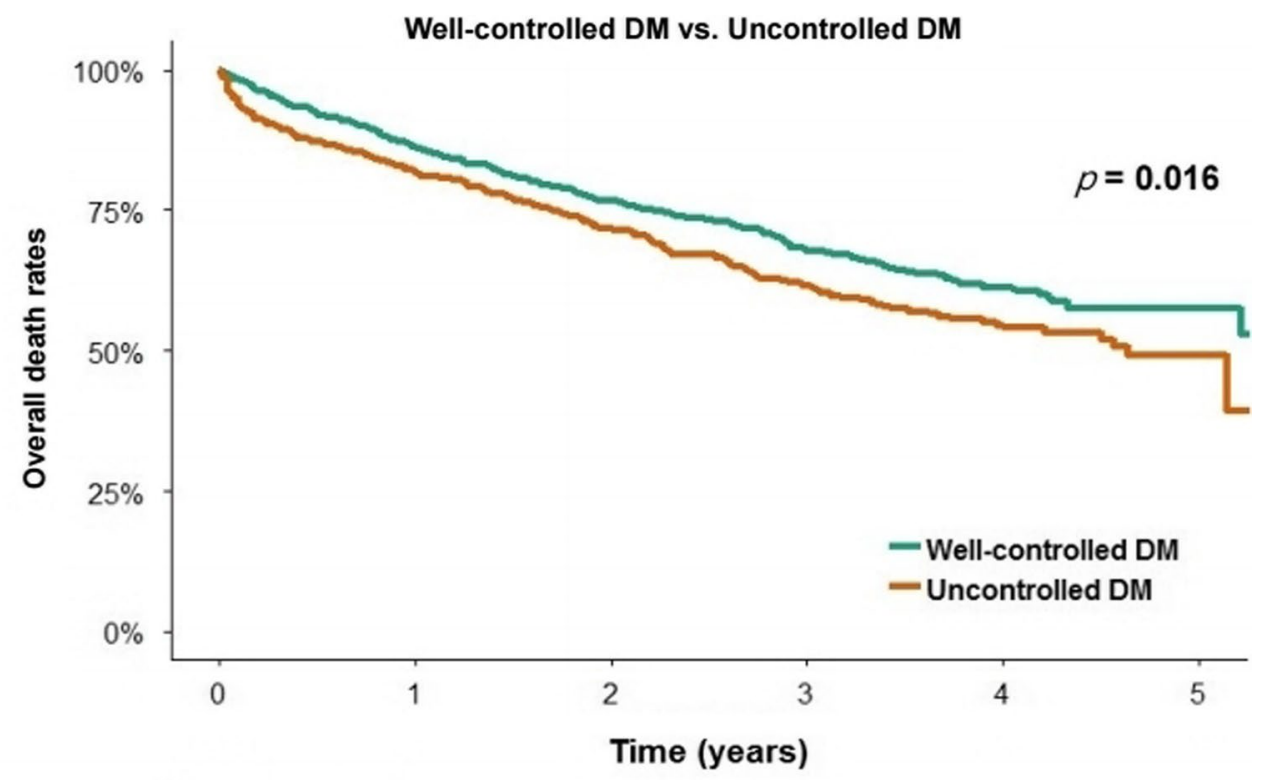

Number at risk

$\begin{array}{rrrrccr}\text { Well-controlled DM } & 587 & 507 & 448 & 307 & 146 & 31 \\ \text { Uncontrolled DM } & 406 & 332 & 287 & 193 & 95 & 11\end{array}$

Fig. 5 Overall all-cause mortality as per glycemic control after discharge in patients with DM. *Well-controlled DM as an $\mathrm{HbA1c}<7.0 \%$ at a follow-up visit within 1 year after discharge; Uncontrolled DM as an $\mathrm{HbA1c} \geq 7.0 \%$

from HFrEF and HFpEF. If HFmrEF is a distinct clinical syndrome or if these patients are in-transition between HFrEF and HFpEF is unknown [39]. Since there were limited patients with HFmrEF in our study, this association needs to be further explored.

Our study has important implications. First, we analyzed one of the largest prospective cohorts comparing the characteristics and clinical outcomes in patients with AHF, with and without DM. Second, our study analyzed baseline echocardiographic findings in all patients, which is unique and challenging to obtain in large HF registries. Third, we evaluated both in-hospital and overall all-cause mortality. This helped estimate both short and long-term impact of DM on mortality in patients with AHF. Fourth, we compared mortality in 3 subtypes of HF based on LVEF. To our best knowledge, this is the first study to evaluate the association of DM with mortality in HFrEF, HFmrEF, and HFpEF. Since the characteristics and prognosis of patients with HFpEF and HFmrEF are unknown, these results may help understand the clinical implications of HFpEF and HFmrEF. Lastly, we also demonstrate that an adequate glycemic control during follow-up was associated with an improved long-term prognosis in patients with AHF and DM.

\section{Limitations}

There are several limitations of our study. First, this is an observational study. To evaluate the effect of glycemic control, it has intrinsic limitations of non-randomized comparisons such as the different distribution of other clinical risk factors and the possibility of unmeasured confounding factors. Second, our endpoint was only all-cause mortality. Detailed clinical outcomes such as cardiovascular death and re-hospitalization for HF may help better understand the impact of DM on outcomes in AHF. Third, many recent studies have evaluated the cardiovascular safety of anti-diabetic medications. While dipeptidyl peptidase 4 (DPP-4) inhibitors had a neutral effect, sodium-glucose co-transporter 2 (SGLT2) inhibitors were most favorable among all classes of anti-diabetic medications for reducing the risk of $\operatorname{HF}[40,41]$. However, SGLT2 inhibitors were not prescribed during the enrollment period of our registry. Therefore, our study could not evaluate their effect on HF.

\section{Conclusions}

Our study, using large registry data with echocardiographic information from all participants, shows that DM is significantly associated with an increased risk of overall mortality in AHF, especially HFrEF. 
Well-controlled diabetes (HbA1c $<7.0 \%)$ was associated with a lower risk of overall mortality compared with uncontrolled diabetes $(\mathrm{HbA} 1 \mathrm{c} \geq 7.0 \%)$ in patients with AHF and DM.

\begin{abstract}
Abbreviations
AHF: Acute heart failure; Cl: Confidence interval; DM: Diabetes mellitus; HF: Heart failure; HFrEF: Heart failure with reduced ejection fraction; HFpEF: Heart failure with preserved ejection fraction; HFmrEF: Heart failure with mid-range ejection fraction; HR: Hazard ratio; LVEF: Left ventricular ejection fraction; NYHA: New York Heart Association.
\end{abstract}

\section{Acknowledgements}

The authors thank all participants and all investigators in the KorAHF registry.

\section{Authors' contributions}

MGK, SYJ wrote the first draft of the manuscript. MGK, HJC, SL, SKP and H-YL designed, interpreted the results and edited the manuscript. JJ, SL and SKP performed statistical analysis of this study. SYJ, SEL, KHK, BSY, SMK, SHB, DJC, ESJ, JJK, MCC, SCC and BHO recruited participants in the KorAHF registry and collected data. All authors read and approved the final manuscript.

\section{Funding}

This study was supported by Research of Korea Centers for Disease Control and Prevention (2010-E63003-00, 2011-E63002-00, 2012-E63005-00, 2013E63003-00, 2013-E63003-01, 2013-E63003-02, and 2016-ER6303-00).

\section{Availability of data and materials}

The data of this study may be available on reasonable request to the Korean Acute Heart Failure (KorAHF) Registry.

\section{Ethics approval and consent to participate}

The study protocol was approved by the Institutional review board or ethics committee at each participating hospital. All patients provided written informed consent for participation in the registry.

\section{Consent for publication}

The authors have reviewed the manuscript and consent for publication.

\section{Competing interests}

The authors have no competing interests.

\section{Author details}

${ }^{1}$ Department of Internal Medicine, Soon Chun Hyang University Hospital, Bucheon, South Korea. ${ }^{2}$ Department of Internal Medicine, School of Medicine, Kyungpook National University, Daegu, South Korea. ${ }^{3}$ Department of Preventive Medicine, Seoul National University College of Medicine, Seoul, South Korea. ${ }^{4}$ Department of Biomedical Science, Seoul National University Graduate School, Seoul, South Korea. ${ }^{5}$ Cancer Research Institute, Seoul National University, Seoul, South Korea. ${ }^{6}$ Department of Internal Medicine, Seoul National University Hospital, Seoul, South Korea. ${ }^{7}$ Department of Internal Medicine, Asan Medical Center, Seoul, South Korea. ${ }^{8}$ Heart Research Center of Chonnam National University, Gwangju, South Korea. ${ }^{9}$ Department of Internal Medicine, Yonsei University Wonju College of Medicine, Wonju, South Korea. ${ }^{10}$ Department of Internal Medicine, Yonsei University College of Medicine, Seoul, South Korea. ${ }^{11}$ Department of Internal Medicine, Catholic University of Korea, Seoul, South Korea. ${ }^{12}$ Department of Internal Medicine, Seoul National University College of Medicine, Seoul National University Bundang Hospital, Seongnam, South Korea. ${ }^{13}$ Department of Internal Medicine, Sungkyunkwan University School of Medicine, Seoul, South Korea. ${ }^{14}$ Department of Internal Medicine, Chungbuk National University College of Medicine, Cheongju, South Korea.

${ }^{15}$ Division of Cardiology, Department of Internal Medicine, Seoul National University College of Medicine, 101 Daehak-ro, Jongno-gu, Seoul 03080, South Korea.

Received: 10 February 2020 Accepted: 25 April 2020

Published online: 02 May 2020

\section{References}

1. Benjamin EJ, Blaha MJ, Chiuve SE, Cushman M, Das SR, Deo R, et al. Heart disease and stroke statistics-2017 update: a report from the American Heart Association. Circulation. 2017;135:e146-603.

2. Ambrosy AP, Fonarow GC, Butler J, Chioncel O, Greene SJ, Vaduganathan $M$, et al. The global health and economic burden of hospitalizations for heart failure: lessons learned from hospitalized heart failure registries. J Am Coll Cardiol. 2014;63:1123-33.

3. Blecker S, Paul M, Taksler G, Ogedegbe G, Katz S. Heart failure-associated hospitalizations in the United States. J Am Coll Cardiol. 2013;61:1259-67.

4. Gheorghiade M, Vaduganathan M, Fonarow GC, Bonow RO. Rehospitalization for heart failure: problems and perspectives. J Am Coll Cardiol. 2013;61:391-403.

5. Lee $\mathrm{SE}, \mathrm{Cho} \mathrm{HJ}$, Lee HY, Yang HM, Choi JO, Jeon ES, et al. A multicentre cohort study of acute heart failure syndromes in Korea: rationale, design, and interim observations of the Korean Acute Heart Failure (KorAHF) registry. Eur J Heart Fail. 2014;16:700-8.

6. Van Deursen VM, Urso R, Laroche C, Damman K, Dahlström U, Tavazzi $\mathrm{L}$, et al. Co-morbidities in patients with heart failure: an analysis of the European Heart Failure Pilot Survey. Eur J Heart Fail. 2014;16:103-11.

7. Aune D, Schlesinger S, Neuenschwander M, Feng T, Janszky I, Norat T, Riboli E. Diabetes mellitus, blood glucose and the risk of heart failure: a systematic review and meta-analysis of prospective studies. Nutr Metab Cardiovasc Dis. 2018;28:1081-91.

8. Nieminen MS, Brutsaert D, Dickstein K, Drexler H, Follath F, Harjola VP, et al EuroHeart Failure Survey II (EHFS II): a survey on hospitalized acute heart failure patients: description of population. Eur Heart J. 2006;27:2725-36.

9. Nichols GA, Gullion CM, Koro CE, Ephross SA, Brown JB. The incidence of congestive heart failure in type 2 diabetes: an update. Diabetes Care. 2004;27:1879-84

10. Dei Cas A, Khan SS, Butler J, Mentz RJ, Bonow RO, Avogaro A, et al. Impact of diabetes on epidemiology, treatment, and outcomes of patients with heart failure. JACC Heart Fail. 2015;3:136-45.

11. De Groote P, Lamblin N, Mouquet F, Plichon D, McFadden E, Van Belle E, Bauters C. Impact of diabetes mellitus on long-term survival in patients with congestive heart failure. Eur Heart J. 2004;25:656-62.

12. MacDonald MR, Petrie MC, Varyani F, Ostergren J, Michelson EL, Young JB, et al. Impact of diabetes on outcomes in patients with low and preserved ejection fraction heart failure: an analysis of the Candesartan in Heart failure: assessment of Reduction in Mortality and morbidity (CHARM) programme. Eur Heart J. 2008;29:1377-85.

13. Gustafsson I, Brendorp B, Seibæk M, Burchardt H, Hildebrandt P, Køber $\mathrm{L}$. Influence of diabetes and diabetes-gender interaction on the risk of death in patients hospitalized with congestive heart failure. J Am Coll Cardiol. 2004:43:771-7.

14. MacDonald MR, Jhund PS, Petrie MC, Lewsey JD, Hawkins NM, Bhagra S, et al. Discordant short- and long-term outcomes associated with diabetes in patients with heart failure: importance of age and sex: a population study of 5.1 million people in Scotland. Circ Heart Fail. 2008;1:234-41.

15. Mebazaa A, Gayat E, Lassus J, Meas T, Mueller C, Maggioni A, et al. Association between elevated blood glucose and outcome in acute heart failure: results from an international observational cohort. J Am Coll Cardiol. 2013:61:820-9.

16. Sarma S, Mentz RJ, Kwasny MJ, Fought AJ, Huffman M, Subacius H, et al. Association between diabetes mellitus and post-discharge outcomes in patients hospitalized with heart failure: findings from the EVEREST trial. Eur J Heart Fail. 2013;15:194-202.

17. Targher G, Dauriz M, Laroche C, Temporelli PL, Hassanein M, Seferovic PM, et al. In-hospital and 1-year mortality associated with diabetes in patients with acute heart failure: results from the ESC-HFA Heart Failure Long-Term Registry. Eur J Heart Fail. 2017;19:54-65.

18. Parissis JT, Rafouli-Stergiou P, Mebazaa A, Ikonomidis I, Bistola V, Nikolaou $M$, et al. Acute heart failure in patients with diabetes mellitus: clinical characteristics and predictors of in-hospital mortality. Int J Cardiol. 2012;157:108-13.

19. Greenberg BH, Abraham WT, Albert NM, Chiswell K, Clare R, Stough WG, et al. Influence of diabetes on characteristics and outcomes in patients hospitalized with heart failure: a report from the Organized Program to Initiate Lifesaving Treatment in Hospitalized Patients with Heart Failure (OPTIMIZE-HF). Am Heart J. 2007;154(277):e1-8. 
20. Kosiborod M, Inzucchi SE, Spertus JA, Wang Y, Masoudi FA, Havranek EP, Krumholz HM. Elevated admission glucose and mortality in elderly patients hospitalized with heart failure. Circulation. 2009;1 19:1899-907.

21. Targher G, Dauriz M, Tavazzi L, Temporelli PL, Lucci D, Urso R, et al. Prognostic impact of in-hospital hyperglycemia in hospitalized patients with acute heart failure: results of the IN-HF (Italian Network on Heart Failure) Outcome registry. Int J Cardiol. 2016;203:587-93.

22. Cleland JG, Chiswell K, Teerlink JR, Stevens S, Fiuzat M, Givertz MM, et al. Predictors of postdischarge outcomes from information acquired shortly after admission for acute heart failure: a report from the PlaceboControlled Randomized Study of the Selective A1 Adenosine Receptor Antagonist Rolofylline for Patients Hospitalized With Acute Decompensated Heart Failure and Volume Overload to Assess Treatment Effect on Congestion and Renal Function (PROTECT) Study. Circ Heart Fail. 2014;7:76-87.

23. Lee SE, Lee HY, Cho HJ, Choe WS, Kim H, Choi JO, et al. Clinical characteristics and outcome of acute heart failure in Korea: results from the Korean Acute Heart Failure Registry (KorAHF). Korean Circ J. 2017:47:341-53.

24. Kristensen SL, Mogensen UM, Jhund PS, Petrie MC, Preiss D, Win S, et al. Clinical and echocardiographic characteristics and cardiovascular outcomes according to diabetes status in patients with heart failure and preserved ejection fraction: a report from the I-preserve trial (Irbesartan in heart failure with preserved ejection fraction). Circulation. 2017;135:724-35.

25. Palau P, Bertomeu-González V, Sanchis J, Soler M, de la Espriella R, Domínguez $E$, et al. Differential prognostic impact of type 2 diabetes mellitus in women and men with heart failure with preserved ejection fraction. Rev Esp Cardiol. 2019;S1885-5857(19):30264-6.

26. Bauters C, Lamblin N, Mc Fadden EP, Van BE, Millaire A, De GP. Influence of diabetes mellitus on heart failure risk and outcome. Cardiovasc Diabetol. 2003:2:1.

27. Glass CK, Olefsky JM. Inflammation and lipid signaling in the etiology of insulin resistance. Cell Metabol. 2012;15:635-45.

28. Falcão-Pires I, Hamdani N, Borbély A, Gavina C, Schalkwijk CG, van der Elden J, et al. Diabetes mellitus worsens diastolic left ventricular dysfunction in aortic stenosis through altered myocardial structure and cardiomyocyte stiffness. Circulation. 2011;124:1151-9.

29. Shimizu I, Minamino T, Toko H, Okada S, Ikeda H, Yasuda N, et al. Excessive cardiac insulin signaling exacerbates systolic dysfunction induced by pressure overload in rodents. J Clin Invest. 2010;120:1506-14.

30. Wong TC, Piehler KM, Kang IA, Kadakkal A, Kellman P, Schwartzman DS, et al. Myocardial extracellular volume fraction quantified by cardiovascular magnetic resonance is increased in diabetes and associated with mortality and incident heart failure admission. Eur Heart J. 2014;35:657-64.

31. Uddin GM, Zhang L, Shah S, Fukushima A, Wagg CS, Gopal K, et al. Impaired branched chain amino acid oxidation contributes to cardiac insulin resistance in heart failure. Cardiovasc Diabetol. 2019;18:86.
32. Tromp J, Voors AA, Sharma A, Ferreira JP, Ouwerkerk W, Hillege HL, et al. Distinct pathological pathways in patients with heart failure and diabetes. JACC Heart Fail. 2020;8:234-42.

33. Ponikowski P, Voors AA, Anker SD, Bueno H, Cleland JGF, Coats AJS, et al. 2016 ESC Guidelines for the diagnosis and treatment of acute and chronic heart failure: the Task Force for the diagnosis and treatment of acute and chronic heart failure of the European Society of Cardiology (ESC) Developed with the special contribution of the Heart Failure Association (HFA) of the ESC. Eur Heart J. 2016:37:2129-200.

34. Fonarow GC, Stough WG, Abraham WT, Albert NM, Gheorghiade M, Greenberg BH, et al. Characteristics, treatments, and outcomes of patients with preserved systolic function hospitalized for heart failure: a report from the OPTIMIZE-HF Registry. J Am Coll Cardiol. 2007:50:768-77.

35. Cheng RK, Cox M, Neely ML, Heidenreich PA, Bhatt DL, Eapen ZJ, et al. Outcomes in patients with heart failure with preserved, borderline, and reduced ejection fraction in the Medicare population. Am Heart J. 2014;168:721-30.

36. Rickenbacher P, Kaufmann BA, Maeder MT, Bernheim A, Goetschalckx K, Pfister $\mathrm{O}$, et al. Heart failure with mid-range ejection fraction: a distinct clinical entity? Insights from the Trial of Intensified versus standard Medical therapy in Elderly patients with Congestive Heart Failure (TIME-CHF). Eur J Heart Fail. 2017;19:1586-96.

37. Tsuji K, Sakata Y, Nochioka K, Miura M, Yamauchi T, Onose T, et al. Characterization of heart failure patients with mid-range left ventricular ejection fraction-a report from the CHART-2 Study. Eur J Heart Fail. 2017:19:1258-69.

38. Bhatia RS, Tu JV, Lee DS, Austin PC, Fang J, Haouzi A, et al. Outcome of heart failure with preserved ejection fraction in a population-based study. N Engl J Med. 2006;355:260-9.

39. Hsu JJ, Ziaeian B, Fonarow GC. Heart failure with mid-range (Borderline) ejection fraction: clinical implications and future directions. JACC Heart Fail. 2017;5:763-71.

40. Nauck MA, McGuire DK, Pieper KS, Lokhnygina Y, Strandberg TE, Riefflin A, et al. Sitagliptin does not reduce the risk of cardiovascular death or hospitalization for heart failure following myocardial infarction in patients with diabetes: observations from TECOS. Cardiovasc Diabetol. 2019;18:116.

41. Yang DY, He X, Liang HW, Zhang SZ, Zhong XB, Luo CF, et al. Comparative outcomes of heart failure among existent classes of anti-diabetic agents: a network meta-analysis of 171,253 participants from 91 randomized controlled trials. Cardiovasc Diabetol. 2019;18:47.

\section{Publisher's Note}

Springer Nature remains neutral with regard to jurisdictional claims in published maps and institutional affiliations.

Ready to submit your research? Choose BMC and benefit from:

- fast, convenient online submission

- thorough peer review by experienced researchers in your field

- rapid publication on acceptance

- support for research data, including large and complex data types

- gold Open Access which fosters wider collaboration and increased citations

- maximum visibility for your research: over $100 \mathrm{M}$ website views per year

At BMC, research is always in progress.

Learn more biomedcentral.com/submissions 